On a new Apparatus for Colour-Combinations

This content has been downloaded from IOPscience. Please scroll down to see the full text. 1884 Proc. Phys. Soc. London 6200

(http://iopscience.iop.org/1478-7814/6/1/316)

View the table of contents for this issue, or go to the journal homepage for more

Download details:

IP Address: 131.91.169.193

This content was downloaded on 07/09/2015 at 08:44

Please note that terms and conditions apply. 
XV. On a new Apparatus for Colour-Combinations. By $\mathrm{H}$. H. Hoffert, B.Sc., A.R.S.M., Assistunt in the Physical Laboratory, South Kensington*.

[Plate XI.]

VARIoUs arrangements for the mixture of colours have already been devised by Maxwell, Rayleigh, Helmholtz, and others, by means of which the laws of colour-combinations have, in their main features, been firmly established.

Wishing to observe for myself the principal phenomena connected with this subject, I have repeated, during the prast winter, many of the experiments thus described, both with the colour-top, and with overlapping spectra. Being desirous of obtaining some convenient arrangement whereby any two or three colours of the spectrum could be combined in any required proportion, and compared with the colours either of naturn! objects or of other spectral combinations, I tried various experiments, using the method first adopted by Maxwell, of observing, by means of a slit-eyepicee, the spectrat produced by light proceeding from illuminated slits, and passing through a train of glass prisms; this method being equivalent to looking through a hole in a screen on to which are cast two or three superposed spectra, so that the colour perceived is that due to the mixture of those parts of the several spectra which fall on the hole.

In these experiments I have been asinted by my colleague Mr. Mitchell, to whom I am also indehted for scereral valuahlo suguestions.

We first tried a modified form of Maxwell's colour-loox, using eventually six equilateral ghass juisms, arrangml in two suts of three symmetrically with resperet to the "yepince; so that if the latter be made a source of linght, the rays are bent throngh allout $150^{\circ}$, and being then received on to a lens, arre focused on to planes situated on either side of the eyepiece, this arrangement being found rery convenient for manijulition.

Movable slits of fixed width, sliding in a frame with hellowscrens of opaque silk between, were used as sources of light,

* Read June 14, 1884. 


\section{"Windina Electromagnets."}

UNES OF FORCE AS SHOWN BY IRON FILINGS.

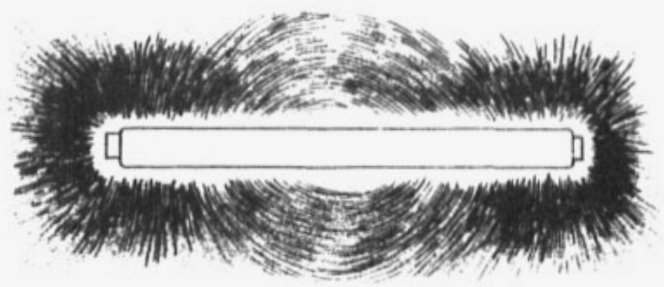

N: 6.

WOUND REQULARLY OVER WHOLE LENGTH.

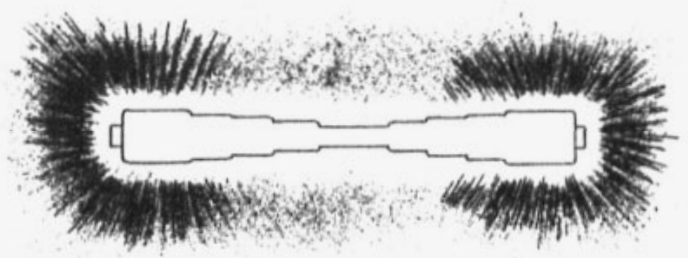

$N: 7$.

WOUND CONED TOWAADS EACH END.

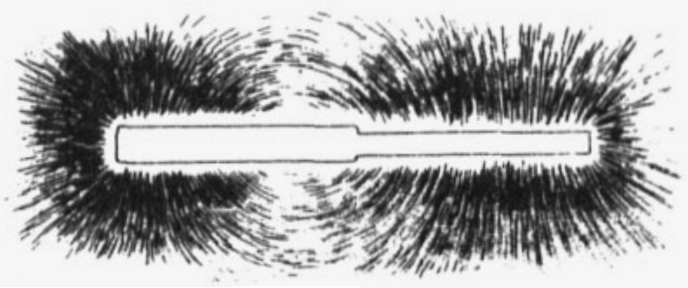

$n * 6$.

WOUNO REOULARLY OVER HALF LENGTH.

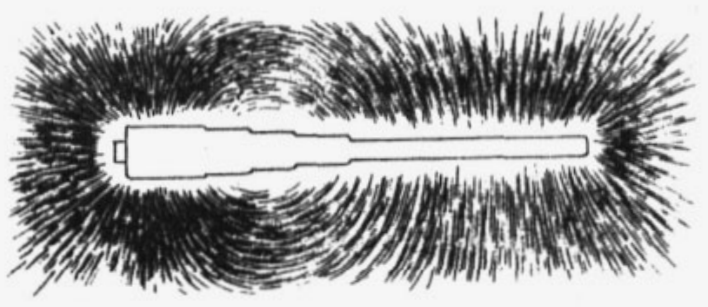

N: 9.

MUUND CONED OVER HALF LENGTH. 
Proc. Phys. Soi. Vol.6.PL.X? APPARATUS FOR COLOUR COMBINATIONS.
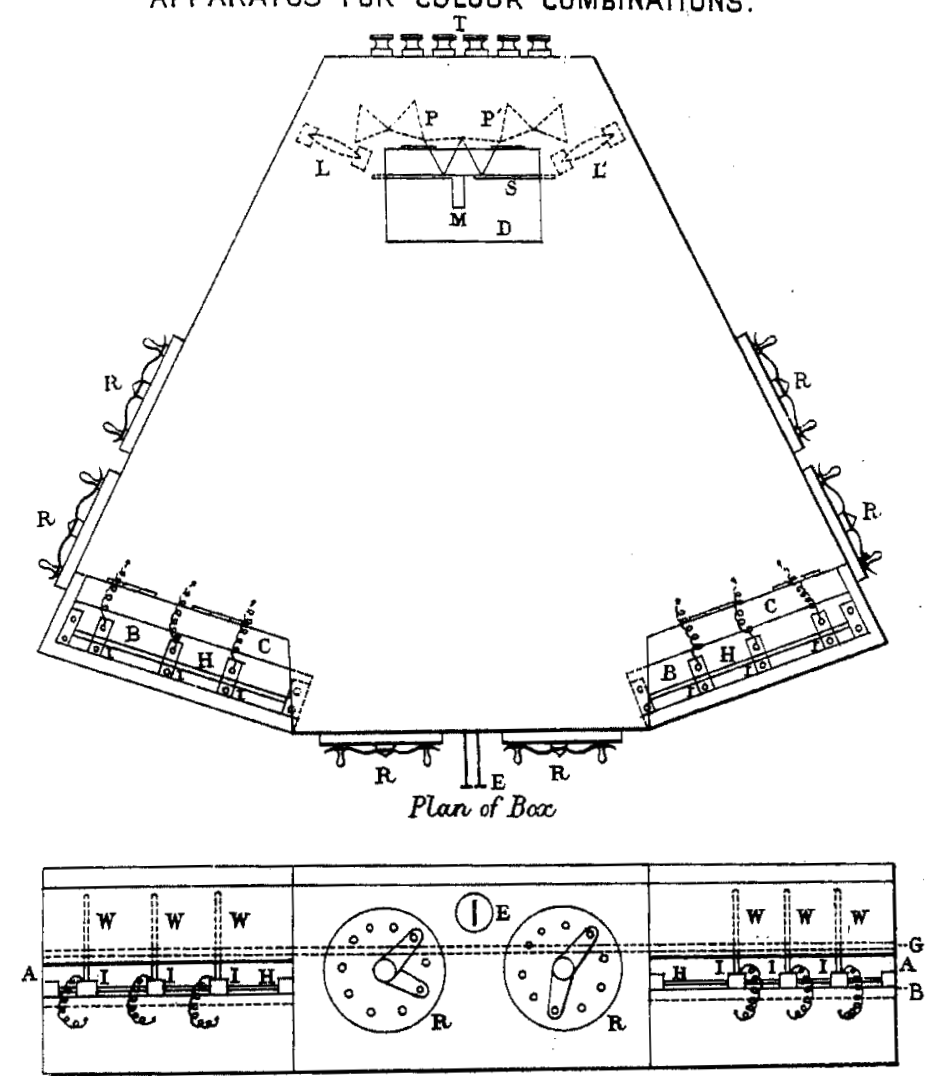

Front Elevationi of Bnx.

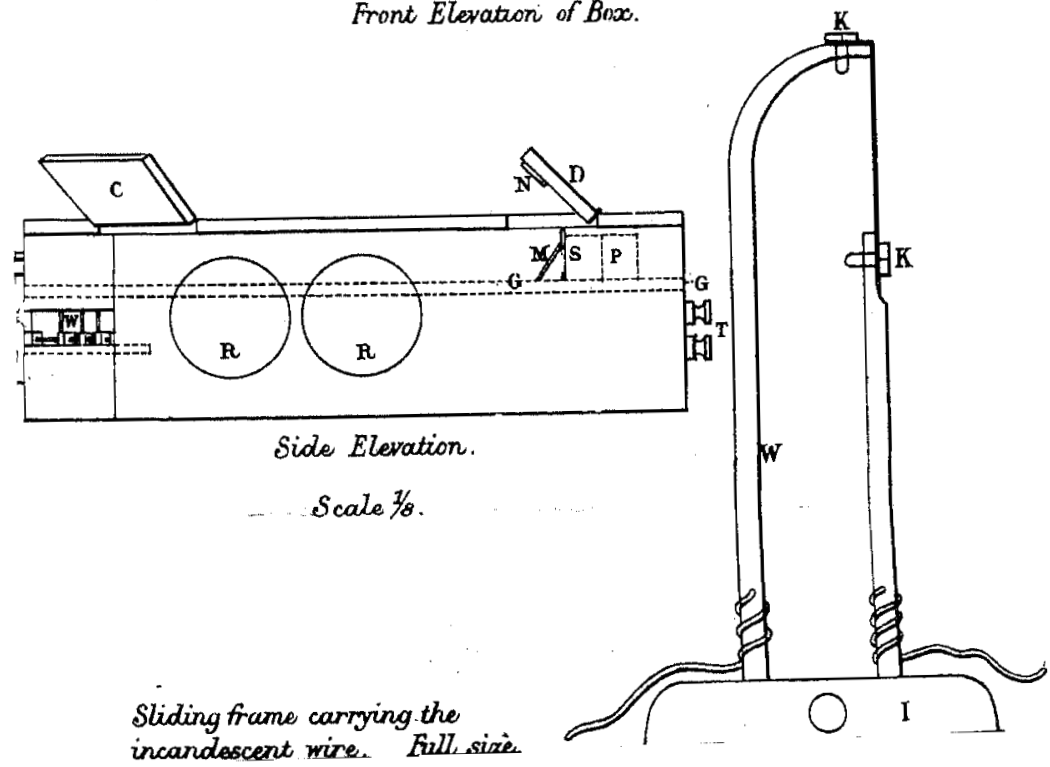


lamps being placed outside them. The intensity of the light was regulated by means of Nicol prisms, one being attached to each slit, so as to be capable of rotation, while an analyzing Nicol was fixed in the eyepiece. The intensity could thus be readily altered for each slit separately.

This arrangement was found to answer fairly well, but its necessarily large dimensions were a great inconvenience. A very long spectrum was needed, as the slits could not be brought very close on account of the size of the Nicol prisms; hence also there was great loss of light.

Movable slits, whether of fixed or adjustable width, are very tronblesome to manipulate, and do not almit of rery rapid and easy adjustment; they were therefore abamilomed altogether, and in their place the light from small lengrths of platinum wire, heated to incandescence by an electric current. wats employed. Preliminary trials having proved satisfictury, the apparatus was constructed which I now bring before your notice.

The prisms, lenses, and sources of light are enclosed in a flat box of irregular hexagonal shape, at the smaller end of which the six prisms (, Pl. XI.) are placed. These are arranged, ats alrealy described, in two sets of three, each prism huing set to mininum deviation. The first prisms have their refiactingedges in contact; and hy means of a screen (S), in which is a small rectangular aperture, small equal strips of the adjacent taces of these prisms are visible from the eyepiece $(\mathrm{E})$, which is a small brass tube with a narrow slit, about $l^{1} 6$ inch wide.

Supposing light to come from the eyepiece, the prisms would deffoct it through about $150^{\circ}$; it would then fill on to two lenses (L), of about 10 inches focal length, which focus the spectra on to the two sides of the box immediately to the right and left of the eyepiece. Here are placed the incandescent wires (W); so that, conversely, if these he thr sourecos of light, the rays follow an inverse course, and the corresponding half of the aperture in the screen is seen illuminaterd with a colour which will depend on the position of the incind scent. wire, and which will be pure and miform if the wire be not too thick, the slit in the eyepiece too wile, or the strip of the prism exposed too larese. The colours are fumbl in pricticen be perfectly unitorm. 
The prisms and lenses are supported at the level of the incandescent wires, on a horizontal floor $(G)$, which divides the box two inches from the top into two compartments, and which is cut away so as to leave a space for the tops of the frames carrying the wires to enter the upper compartment. These frames $(W)$, which are six in number, three on each side, consist of brass wires held on small ebonite blocks (1), which slide along a steel rod $\left(\mathrm{I}_{\mathrm{L}}\right)$ supported on a ledge inside the hox. The frumes can be moved along the length of the spectrum from outsido by means of openings (A) cut in the sides of the box, into which the hands can be introduced. These openings ure below the level of the horizontal floor, so that the upper compartment, which is everywhere blackened inside, is quite impervious to external light, unless the lids in tho cover of the box, to be presently described, are opened.

The frames are connected by flexible wires to a series of resistances arranged in the lower compartment of the box; and by means of six dials (R), on the sides of the box, each of the six circuits can bo altered in resistance at will, so that the incandescent wires can be rapidly adjusted, whether in position or in intensity, by the observer without his baving to remore his eye from the evepiece. Six prairs of binding-screws (T) at the back of the box comnect the six circuits with a Grove battery. By this means, when the current is passing, the aperture in the screen is seen divided into two coloured strips in close juxtaposition; one colour being that due to the wires and prisms on the right hand, the other to those on the left. The colours can thus be readily compared and adjusted to exact identity.

It remains to describe the means by which external colours can be introduced for comparison with those produced by the prisms.

'The cover of the box contains three small hinged lids. Two of these (C) are over the luminous wires, and serve to adjus or replace the wires in case of accidental fusion. The third lil (1) opens over the space just in front of the screen. Here is placed a small strip of microscope cover-glass ( $M$ ), inclined at about $60^{\circ}$ to the horizontal, and so arranged that, as seen from the eyepiece, it exactly covers that portion of the aperture in the screen which is illuminated by the light from the 
left-hand train of prisms, this light being thas seen througl the glass slightly diminished in intensity. On the undersido of the lid is a small silvered mirror $(\mathrm{N})$; and by raising thes lid to the proper height, the colour of any object laid on the top of the box is seen by double reflection in the eyepiece, 'xactly coinciding with the left lalf' of the alyerture in the" screen. This colour may be either combined with that fron the left-hand train of prisms, or compared with that from the right-band train. For white light I use the light from a window, which may be reduced in intensity to any desired amount by passing it through one or more pieces of roughened glass, held in a frame placed on the top of the box. Coloured glasses, or cells of coluured fluids, can similarly be placed in the frane, so that almost every possible combination or comparison of colours may be made. Another frame, which may he placed inside the box between the screen and the eyepiece, serves to show the action of different absorbing media on colours identical in appearance but of different composition.

The colours produced are uniform, very constant, and fairly bright. Those from the blue and violet parts of the spectrum are necessarily more deficient in luminosity. This is partially compensated by using in the less luminous parts of the spectrum ribbons of platinum, produced by rolling out the wires, with their flat surfaces turned towards the lenses. This is equivalent to increasing the width of the slit in ordinary arrangements. Should the wires become fused through incautiously using too strong a current, they can be very readily replaced by means of the screws $(K)$.

For the current, three Grove's cells are needed for each of the ribbons and two for each of the wires. But since tho frames carrying the wires can be brought together till the wires are nearly in contact, and since the wires themselves offer extremely narrow luminous surfaces, a very long spectrum is not needed; and by using more powerful lenses and bringing the sliding frames closer to them, a greater intensity of light would result; while the size of the box might thus he reduced to one half or even less of its present amount, the eyspiece being kept at a sufficient distance by the use of a longer tube, which might be made removable. One Grove 
cell would then suffice for ach wire, or at most two when experimenting on the violet rays.

Instead of the step-by-step dial-resistances, some arrangement giving, like the rheostat, a gralual adjustment of the intensity would bo perlaps preferable.

Scales can be attached in front of the sliding frames to show the exact position in the spectrum of ench of the luminous wires.

I trust that the ease and rapidity with which the adjustments in this alpraratus can bo made will cause it to be found useful in those many cases in which it is impossible or inconvenient to make use of the more powerful effect of direct sunlight.

XVI. On a Method of Measuring the Electrical Capacity of a Condenser, and on the Determination by Electrical Observtions of the Period of a Truning-fork. By R. T. GLazebrook, M.A., F.R.S., Demonstrator of Experimental Plysics "the Cacendish Laboratory, Cambirdge*.

Tnis experiments described in the following paper were undertaken at the request of Messis. Latimer Clark, Muirhead, and Co., for the purpose of testing one of their condensers "which," quoting from a letter from the firm, "has lately been made and which we use in the factory. In its construction it is the same as all our condensers, and is made of sheets of mica and tinfoil and laid with paraftin-wax."

The method employed was a modification of one given by Maxwell (vol, ii. $\$ 776$ ), and used by J. J. Thomson (Phil. Trans. iii. 1883) in his recent determination. The following is his description of the arrangement :-

"In a Wheatstone bridge, A B CD (figr. 1), with the galvanometer at $G$ and the battery between $A$ and $B$, the circuit $B D$ is not closed, but the points 13 and 1$)$ are connected with two poles, $R$ and $\mathrm{S}$, of a commutator, between which a travelling piece, $P$, moves backwards and forwards. $P$ is connected with one plate of a condenser, the other plate of which is conncicted Fig. 1.

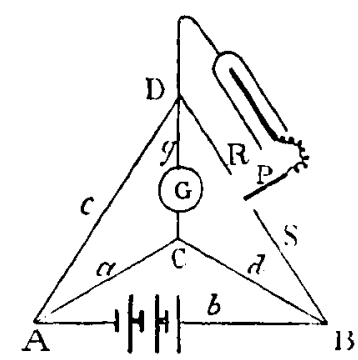

* Reidd June $28,1+84$. 